\title{
A CLINICOPATHOLOGICAL STUDY OF NEUROFIBROMATOSIS TYPE 1 IN A TERTIARY LEVEL CARE CENTRE
}

\author{
${ }^{1}$ HOD, Department of Dermatology \& Venereology, Chengalpattu Medical College. \\ ${ }^{2}$ Assistant Professor, Department of Dermatology \& Venereology, Chengalpattu Medical College. \\ 3Junior Resident, Department of Dermatology \& Venereology, Chengalpattu Medical College. \\ ${ }_{4}^{4}$ Assistant Professor, Department of Dermatology \& Venereology, Chengalpattu Medical College. \\ 5 Associate Professor, Department of Dermatology \& Venereology, Chengalpattu Medical College. \\ ${ }^{6}$ Assistant Professor, Department of Dermatology \& Venereology, Chengalpattu Medical College. \\ 7 Junior Resident, Department of Dermatology \& Venereology, Chengalpattu Medical College. \\ 8Junior Resident, Department of Dermatology \& Venereology, Chengalpattu Medical College.
}

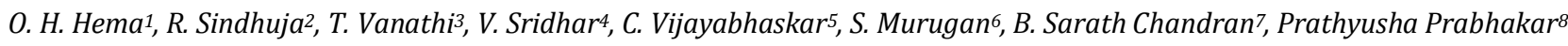

\begin{tabular}{l}
\hline ABSTRACT \\
\hline BACKGROUND \\
Neurofibromatosis type 1 (NF1) is an autosomal dominant disorder, and its diagnosed with a set of clinical criteria and \\
histopathological examination of skin lesions. This study was designed to evaluate the clinical and pathologic pattern of NF1 among \\
patients attended OPD in Chengalpattu Medical College.
\end{tabular}

\section{METHODS AND MATERIALS}

A retrospective clinical and histopathological case study of 50 patients diagnosed as NF1 were studied over a period of 1 year (April 2014-March 2015) at Chengalpattu Medical College.

\section{RESULTS}

50 patients were taken up for study with 31 males and 19 females (ratio 3:2) aged 1-99 (Mean \pm S.D. $=3.4 \pm 1.7$ ) years. All patients had neurofibromas, and were benign, while 49 (99\%) patients had cafe-au-lait spots. Benign neurofibromas were clinically cutaneous [38 (76\%)], subcutaneous [9 (18\%)], segmental [1 (2\%)] and plexiform [2 (4\%)]. Sites of distribution of neurofibromas included the extremities (50\%), trunk (30.4\%), head and neck (9.4\%), and other sites $(10.2 \%)$.

\section{CONCLUSIONS}

In our setting, NF1 is more common among males, with the highest density of neurofibromas covering the extremities and trunk.

\section{KEYWORDS}

Cafe-Au-Lait Macules, Freckles.

HOW TO CITE THIS ARTICLE: Hema OH, Sindhuja R, Vanathi T, et al. A clinicopathological study of neurofibromatosis type 1 in a tertiary level care centre. J. Evolution Med. Dent. Sci. 2016;5(52):3429-3433, DOI: 10.14260/jemds/2016/792

\section{INTRODUCTION}

Neurofibromatosis type 1 (NF1) is an autosomal dominant genetic disorder with high penetrance and variable expressivity. ${ }^{1-3}$ Approximately, $50 \%$ of cases have a family history of autosomal dominant transmission and the remaining appear to represent a new mutation. ${ }^{3}$ An estimated prevalence of 1 in 2000-4000 live births has been identified in all ethnic groups and two to three million individuals are affected worldwide. ${ }^{2}$ The most common manifestations of NF1 in the skin is characterized by abnormal pigmentation and numerous cutaneous or subcutaneous neurofibromas, which are pathognomonic of NF1. Since then, diagnosis has been based on the presence of neurocutaneous stigmata such as cafe-au-lait spots, axillary, inguinal freckling and cutaneous or subcutaneous neurofibromas and iris hamartomas (Lisch nodules)..$^{3-4}$

Financial or Other, Competing Interest: None.

Submission 27-04-2016, Peer Review 05-06-2016,

Acceptance 11-06-2016, Published 30-06-2016.

Corresponding Author:

Dr. R. Sindhuja

Department of Dermatology \& Venereology,

Chengalpattu Medical College,

Chengalpattu-603001.

E-mail:dhunsi75@gmail.com

DOI: $10.14260 /$ jemds/2016/792
Recent advances in molecular genetics via gene mapping by restriction fragment length polymorphism have localized the defective NF1 gene to long arm of chromosome 17 (Chromosome band 17 q11.2) making genetic diagnosis possible. The purpose of this work was to study the clinical and pathologic pattern of NF1 patients managed in this institution over a period of 1 year (2014-2015).

\section{MATERIALS AND METHODS}

This was a retrospective study of 50 patients clinically diagnosed as NF1. The skin tumours were excised and submitted to the histopathological examination. Haematoxylin and eosin (H\&E) sections were retrieved and reviewed. In a few cases, the paraffin blocks were retrieved and fresh sections were cut for H\&E stains. All patients satisfied the clinical criteria for the diagnosis of NF1.

Clinical data including age, sex, duration of signs and symptoms, as well as type and site distribution of neurofibromas were obtained from case notes. All the patients were referred to ophthalmologist to identify Lisch nodules by a slit lamp biomicroscopy. All patients had cranial computerized tomographic (CT) scanning performed.

\section{RESULTS}

There were 50 patients comprising 31 (62\%) males and 19 $(38 \%)$ females giving a male to female ratio of $3: 2$. The ages of 
the patients ranged from 1 to 99 years with a Mean \pm SD. of $3.4 \pm 1.7$ years. The peak age of incidence was at the third decade (Fig. 1). Male patients outnumbered females in all age groups. The clinical duration between onset of first sign to presentation ranged from 1-24 years. $55 \%$ of patients presented within 5 years, 33\% between 5 and 10 years and remaining 10 years above after onset of the first clinical sign. Clinically, all 50 patients had neurofibromas, among which cafe-au-lait macules occurred in 49 (99\%) patients (Table 1).

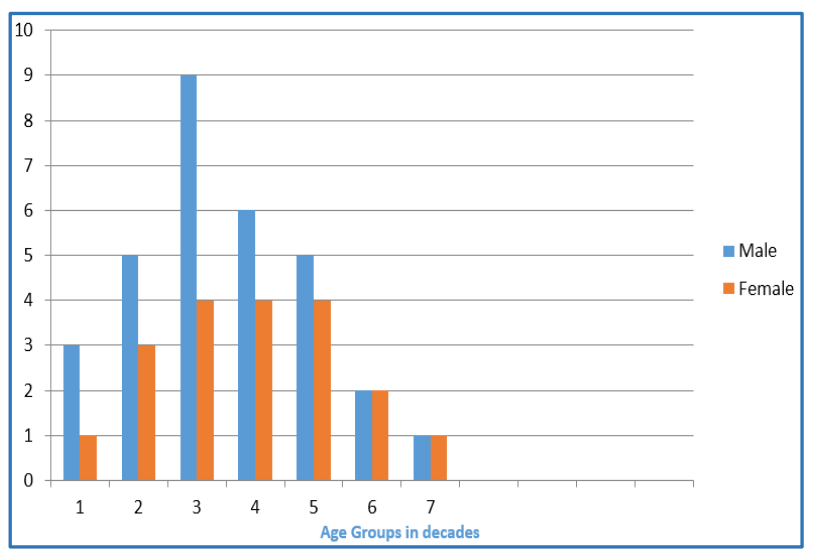

Fig. 1: Age and Sex Distribution in 50 Cases of Neurofibromatosis Type 1 (NF1)

Clinically, the predominant types of neurofibroma were cutaneous [38, 76\%) (Fig. 2a), subcutaneous (9, 18\%) (Fig. $2 \mathrm{~b}$ ), segmental (1,2\%) (Fig. 2c), and plexiform (2, 4\%) (Fig. 2d) (Table 2). In $60 \%$ of the cases, there were mixed types of neurofibromas. Lisch nodule was present in 30 out of 50 patients $(60 \%)$ examined by slit lamp, 1 patients screened with cranial CT had ventricular dilatation with aqueductal stenosis and all patient had axillary or inguinal freckling.

\begin{tabular}{|c|c|c|c|}
\hline $\begin{array}{c}\text { Clinical } \\
\text { Feature }\end{array}$ & $\begin{array}{c}\text { Patients } \\
\text { Examined }\end{array}$ & $\begin{array}{c}\text { Patients } \\
\text { Affected }\end{array}$ & Percent \\
\hline $\begin{array}{c}\text { Neurofibromas } \\
(>2)\end{array}$ & 50 & 50 & 100 \\
\hline $\begin{array}{c}\text { Cafe-au-lait Macules } \\
(>6)\end{array}$ & 50 & 49 & 99 \\
\hline Lisch Nodules (1-2) & 50 & 30 & 60 \\
\hline $\begin{array}{c}\text { Axillary/Inguinal } \\
\text { Freckling }\end{array}$ & 50 & 50 & - \\
\hline $\begin{array}{c}\text { Short stature and } \\
\text { Macrocephaly }\end{array}$ & 50 & 1 & 2 \\
\hline $\begin{array}{c}\text { First Degree Relative } \\
\text { with NF1 }\end{array}$ & 50 & 10 & 20 \\
\hline $\begin{array}{c}\text { Ventricular Dilation } \\
\text { with }\end{array}$ & 50 & 1 & 2 \\
Aqueductal Stenosis \\
on CT
\end{tabular}$\quad \begin{gathered}\text { Table 1: Clinical Presentation of } \\
\text { Neurofibromas Type 1 in 50 Patients }\end{gathered}$

$\mathrm{CT}=$ Computerized tomography.

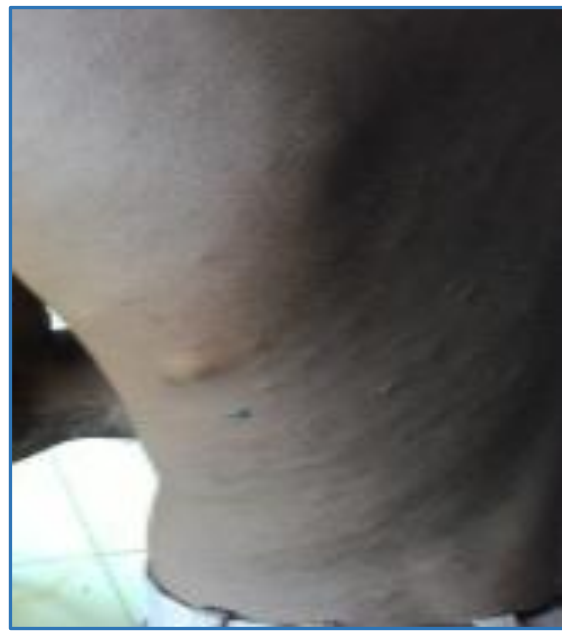

Fig. 2A: Cutaneous

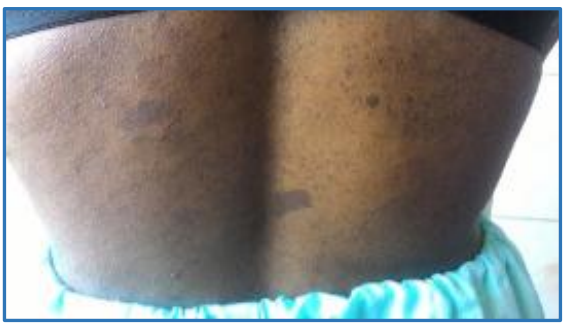

Fig. 2B: With Freckles

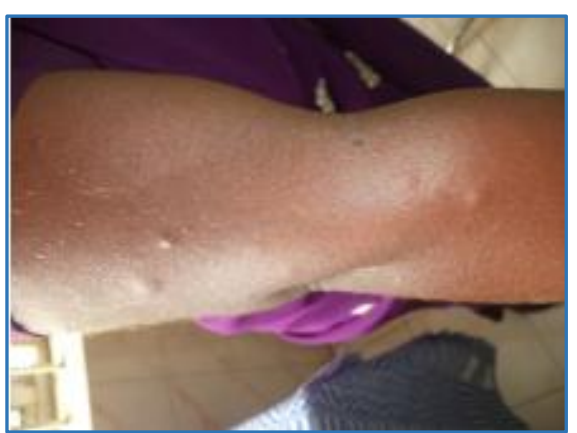

Fig. 2C: Segmental

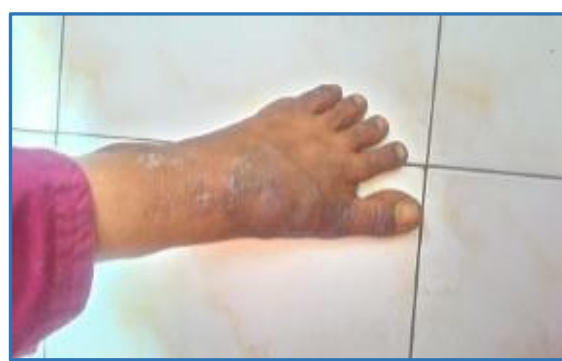

Fig. 2D: Plexiform

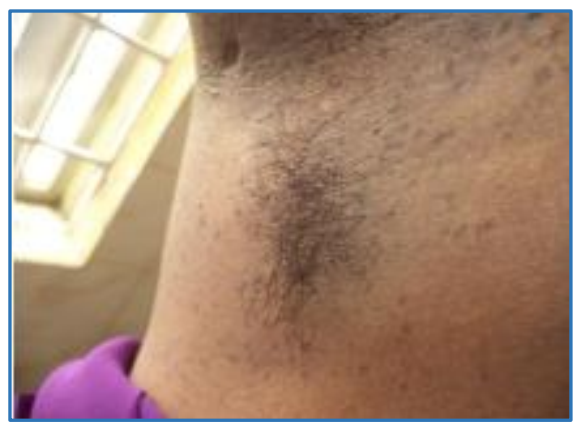

Fig. 2E: Axillary freckling 


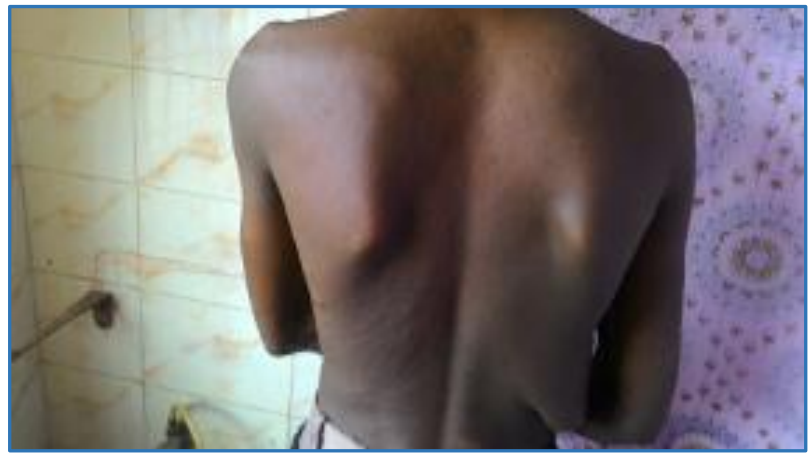

Fig. 2F: Plexiform type

Table 2 shows the site, distribution, and type of neurofibromas. The commonest site was the upper limb followed by the lower limbs and the trunk. Other sites were head, neck, and multiple sites. Neurofibromas were benign (Fig. 3) in all (100\%) patients.

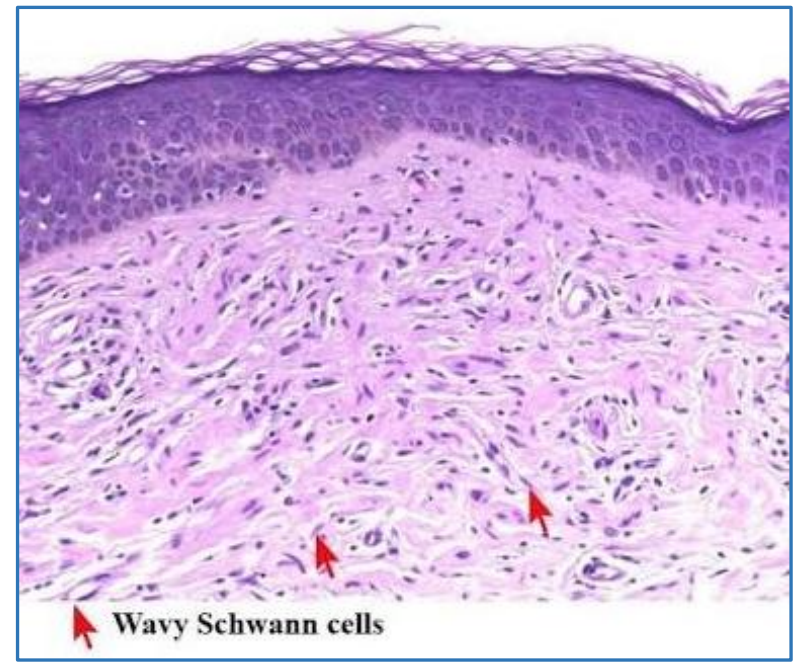

Fig. 3: Benign Subcutaneous Skin Nodule (Neurofibroma) from a Case of Neurofibromatosis Type 1 showing Bands of Elongated Spindle Cells Arranged in Parallel and Wavy Rows in an Oedematous Loose Matrix

\begin{tabular}{|c|c|c|c|c|c|c|}
\hline Neurofibromas & $\begin{array}{c}\text { Head } \\
\text { \& } \\
\text { Neck }\end{array}$ & Trunk & Extremities & $\begin{array}{c}\text { Other } \\
\text { Sites }\end{array}$ & Total & Percent \\
\hline $\begin{array}{c}\text { Benign } \\
\text { neurofibromas }\end{array}$ & & & & & & \\
\hline Cutaneous & 3 & 11 & 19 & 5 & 38 & 76 \\
\hline Subcutaneous & 1 & 2 & 5 & 1 & 9 & 18 \\
\hline Plexiform & 0 & 1 & 1 & 0 & 2 & 4 \\
\hline Segmental & 0 & 0 & 1 & 0 & 1 & 2 \\
\hline $\begin{array}{c}\text { Total } \\
\text { Percent) }\end{array}$ & $\mathbf{9 . 4}$ & $\mathbf{3 0 . 4}$ & $\mathbf{5 0}$ & $\mathbf{1 0 . 2}$ & $\mathbf{5 0}$ & $\mathbf{0}$ \\
\hline \multicolumn{7}{|c|}{ Table 2: Site Distribution of Neurofibromas } \\
in Neurofibromatosis Type1 \\
\hline
\end{tabular}

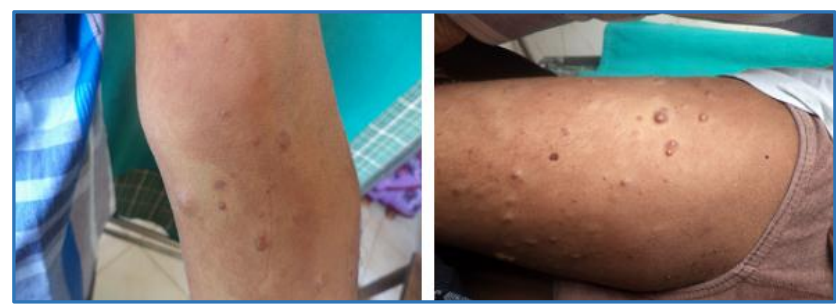

Fig. 4: Neurofibroma Associated with Hansen's Disease
Table 3 shows the diseases associated with neurofibromatosis. The common associated disease was pruritus, which was seen in 25 percent followed by hypertension found in 10 patients.

\begin{tabular}{|c|c|c|}
\hline Sl. No. & Disease Associated & No. of Patients \\
\hline 1 & Ureteric Colic & 1 \\
\hline 2 & Lichen Planus & 2 \\
\hline 3 & Hansen's disease & 1 \\
\hline 4 & Pruritus & 25 \\
\hline 5 & Psoriasis & 1 \\
\hline 6 & Vitiligo & 1 \\
\hline 7 & Arteriovenous Malformation & 1 \\
\hline 8 & Hypertension & 10 \\
\hline \multicolumn{3}{|c|}{ Table 3: Shows the Diseases Associated } \\
with Neurofibromatosis \\
\hline
\end{tabular}

\section{DISCUSSION}

Neurofibromatosis type 1 belongs to the group of neurocutaneous syndromes and is the commonest form of neurofibromatosis accounting for greater than $90 \%$ of all cases. ${ }^{1}$ Riccardi classified NF into following clinical types. ${ }^{5}$

- NF1-Von Recklinghausen's disease.

- NF2-Acoustic.

- NF3-mixed (Multiple brain and spinal tumours with CALM and neurofibroma; CALMs are large, pale, and fewer than in NF1).

- $\quad$ NF4-variant (Both neurofibroma and CALM are present; CALM may spontaneously disappear).

- NF5-segmental (CALM and/or neurofibroma is limited to a unilateral segment; non-familial).

- NF6-CALM (Multiple CALM without neurofibroma; familial/sporadic).

- NF7-late-onset (Manifestations after 20 years of age; CALMs may be absent).

- NF8-Not otherwise specified (Definite NF, but not characteristic of any other category; CALMs may be absent.

The clinical manifestations of NF1 and diagnosis have been documented. 1-4 $^{-}$This review a retrospective study has attempted to illustrate the clinicopathology pattern of NF1 in our outpatient department. Diagnosis were easily ascertained using NIHCDC (National Institute of Health Consensus Development Conference) diagnostic criteria. ${ }^{4}$

Criteria Requires two or more of the following Criteria to be Fulfilled.

1. Six or more cafe-au-lait macules of over $5 \mathrm{~mm}$ in greatest diameter in prepubertal individuals and over $15 \mathrm{~mm}$ in greatest diameter in postpubertal individuals.

2. Two or more neurofibromas of any type or one plexiform neurofibroma.

3. Freckling in the axillary or inguinal regions.

4. Optic glioma.

5. Two or more Lisch nodules.

6. A distinctive osseous lesion such as sphenoid dysplasia or thinning of the long bone cortex with or without pseudoarthrosis.

7. A first-degree relative (Parent, sibling, offspring) with NF1 by the above criteria. 
Cafe-au-lait macules (CALMs) are sharply defined, lightbrown patches that vary in size from 0.5 to $50 \mathrm{~cm}$. CALMs are the first feature of the disease to appear in all children. ${ }^{1,6}$

Cutaneous neurofibromas (Previously termed mollusca fibrosa) are soft, lilac-pink tumours, sessile and dome-shaped, sometimes pedunculated. These lesions are most numerous on the trunk and limbs; hundreds may be present, ranging from a few millimetres to several centimetres in diameter.

The plexiform neurofibroma is a diffuse elongated fibroma along the course of a nerve frequently involving the trigeminal or upper cervical nerves and usually noticeable within the first 2 years of life. Plexiform neurofibromas have a distinctive "bag of worms' feeling on palpation. Elephantiasis neurofibromatosa is a similar diffuse neurofibromatosis of nerve trunks associated with overgrowth of the subcutaneous tissue and of the skin, which is wrinkled and pendulous and may produce gross disfigurement. Neurofibromas may also involve the viscera and blood vessels.

Freckling occurs frequently in the axillae, when it is virtually pathognomonic (Crowe's sign). ${ }^{7}$ It is present in about $70 \%$ of affected subjects and appears a little later than the cafe-au-lait spots, the youngest case in one series being 3 years old. ${ }^{13}$ It may also occur in other intertriginous areas, especially the groin.

There may also be darker pigmented patches over an underlying plexiform neurofibroma and if these extend to the midline of the spine it may indicate that the tumour involves the spinal cord. ${ }^{8}$

Lisch nodules (Pigmented iris hamartomas) appear as dome-shaped lesions found superficially around the iris on slit-lamp examination.

They occur in over $90 \%$ of patients and increase in incidence with age. ${ }^{1,6}$ They are asymptomatic, but help to confirm the diagnosis. They do not occur in segmental or bilateral acoustic NF. ${ }^{9}$

Skeletal abnormalities are well described in NF1 possibly due to defect in osteoblast differentiation secondary to NF1 status. Kyphoscoliosis occurs in $2 \%$ of cases.

Pseudoarthrosis involving the tibia or radius occurs in $1 \%$, but may be asymptomatic. ${ }^{1}$ Sphenoid wing dysplasia is a characteristic abnormality.

\section{Endocrine Disturbances of Many Types may be Associated.10}

Precocious puberty, acromegaly. ${ }^{11}$ Addison's disease, hyperparathyroidism, gynaecomastia and pheochromocytoma.

The most common solitary intracranial tumour is an optic nerve glioma; astrocytomas, and schwannomas.

Our patients presented very late despite early onset of clinical signs. Approximately, $40 \%$ of our cases were diagnosed during the 3rd and 4th decades of life. This contrasts with reports from Western countries where $94 \%$ of cases were diagnosed with certainty at the age of 6-8 years. ${ }^{12,13}$ In this series, NF1 was found to be more common in males than females as also reported by Ademuluyi et al. ${ }^{14}$

Whereas cafe au lait (80-95\%), Iris Lisch nodules (66.9\%) and peripheral neurofibromas (49\%) were reported in other studies. $3,15,16,17$ the order of incidence of major clinical features of NF1 in the present study differs significantly from these reports. Neurofibromas occurred in all our patients (100\%), while cafe au lait macules were detected in $99 \%$, and Lisch nodules in $60 \%$, axillary or inguinal freckling(100\%).

The presence of Lisch nodules is unique to NF1 and is best seen by slit lamp biomicroscopy examined in ophthalmic department. Patients were also subjected to neurologic assessment and neuroradiological investigation.

Neurofibromas occurred in $100 \%$ of our patients, contrary to reports from other studies, which ranged from 46 to $53 \% .3,17$ This was expected as the patients were primarily referred to the surgeons based on the presence of these lesions. However, the finding of cutaneous and subcutaneous neurofibromas as the most common forms of neurofibromas in this series corroborates the findings in other studies. 2,12,16,17 We observed that neurofibromas were located more at the extremities and the trunk than head and neck. The extremities were the commonest site (50\%) followed by the trunk (30.4\%) and the head and neck (9.4\%).

Minor disease features such as short stature and macrocephaly were observed in 1 patient, learning disability was found in 4 patients. Recognized disease complications of NF1 include plexiform neurofibroma, optic gliomas, scoliosis. 3,15 Only 2 plexiform neurofibromas were observed accounting for $4 \%$, which is low compared with other studies. ${ }^{3,16}$ Another recognized complication of NF1 is central nervous system malignancy, which were not observed. Optic gliomas, scoliosis were not seen in any patient. Segmental neurofibroma, which was one of rarest presentation observed.

\section{CONCLUSION}

NF1 is commoner among males with the highest density of neurofibroma distribution being over the extremities and trunk.

\section{REFERENCES}

1. Huson SM, Harper PS, Compton DA. Von Recklinghausen neurofibromatosis a clinical and population study in south-east wales. Brain 1988;111(Pt 6):1355-81.

2. Sampson JH, Martuza RL. Neurofibromatosis and other phakomatoses. In: Wilkins RH, Rengachary SS, (eds). Neurosurgery, $2^{\text {nd }}$ ed. EDZ, Part 6 Neuro-Oncology. New York: McGraw-Hill, health professions division 1996;1:673-6.

3. North K, Gutmann DH. The clinical manifestations of NF1: patient review. In: Bax MCO, Davies P, (eds). Neurofibromatosis type 1 in childhood (international review of child neurology series). London: Mac Keith Press 1997:17-38.

4. National institutes of health consensus development conference. Neurofibromatosis conference statement. Arch neurol 1988;45(5):575-8.

5. Riccardi VM. Neurofibromatosis: clinical heterogeneity. Curr probl Cancer 1982;7(2):1-34.

6. Huson SM, Compston DA, Harper PS. A genetic study of von Recklinghausen neurofibromatosis in south east Wales II guidelines for genetic counselling. J Med Genet 1989;26(11):712-21.

7. Crowe FW. Axillary freckling as a diagnostic aid in neurofibromatosis. Ann Intern Med 1964;61(6):1142-3.

8. Riccardi VM. Pathophysiology of neurofibromatosis IV dermatologic insights into heterogeneity and pathogenesis. J Am Acad Dermatol 1980;3(2):157-66. 
9. Riccardi VM. Von Recklinghausen neurofibromatosis. N Engl J Med 1981;305(27):1617-27.

10. Saxena KM. Endocrine manifestations of neurofibromatosis in children. Am J Dis Child 1970;120(3):265-71.

11. Hartemann P, Schmitt J, Arnould G. Acromegalie et neurofi bromatose de Recklinghausen a propos de dix cas. Ann Endocrinol 1964;25:601-18.

12. Riccardi VM. Neurofibromatosis: phenotype, natural history and pathogenesis. In: Guillevin L, (edn). Neurofibromatosis: phenotype, national history and pathogenesis, $2^{\text {nd }}$ ed. Baltimore: John Hopkins University Press 1992:81-5.

13. DeBella K, Szudek J, Friedman JM. Use of the national institutes of health criteria for diagnosis of neurofibromatosis 1 in children. Paediatrics 2000;105(3Pt 1):608-14.
14. Ademuluyi SA, Sowemimo GO, Oyeneyin JO. Surgical experience in the management of multiple neurofibromatosis in Nigerians. West Afr J Med 1989;8(1):59-65.

15. Huson SM. Recent developments in the diagnosis and management of neurofibromatosis. Arch Dis Child 1989;64(5):745-9.

16. Roos KL, Dunn DW. Neurofibromatoses. CA-A Cancer J for Clinicians 1992;42(4):241-54.

17. McGaughvan JM, Harris DI, Donnai D, et al. A clinical study of type 1 neurofibromatosis in North West England. J Med Genet 1999;36(3):197-203. 